\title{
Future Changes in Hail Occurrence in the United States Determined through Convection-Permitting Dynamical Downscaling $\mathscr{O}$
}

\author{
ROBERT J. TRAPP \\ Department of Atmospheric Sciences, University of Illinois at Urbana-Champaign, Urbana, Illinois \\ KIMBERLY A. HOOGEWIND ${ }^{\mathrm{a}}$ \\ Department of Earth, Atmospheric, and Planetary Sciences, Purdue University, West Lafayette, Indiana \\ SONIA LASHER-TRAPP \\ Department of Atmospheric Sciences, University of Illinois at Urbana-Champaign, Urbana, Illinois
}

(Manuscript received 1 November 2018, in final form 28 April 2019)

\begin{abstract}
The effect of anthropogenically enhanced greenhouse gas concentrations on the frequency and intensity of hail depends on a range of physical processes and scales. These include the environmental support of the hailgenerating convective storms and the frequency of their initiation, the storm volume over which hail growth is promoted, and the depth of the lower atmosphere conducive to melting. Here, we use high-resolution (convection permitting) dynamical downscaling to simultaneously account for these effects. We find broad geographical areas of increases in the frequency of large hail ( $\gtrsim 35-\mathrm{mm}$ diameter) over the United States, during all four seasons. Increases in very large hail $(\gtrsim 50-\mathrm{mm}$ diameter) are mostly confined to the central United States, during boreal spring and summer. And, although increases in moderate hail ( $\gtrsim 20-\mathrm{mm}$ diameter) are also found throughout the year, decreases occur over much of the eastern United States in summer. Such decreases result from a projected decrease in convective-storm frequency. Overall, these results suggest that the annual U.S. hail season may begin earlier in the year, be lengthened by more than a week, and exhibit more interannual variability in the future.
\end{abstract}

\section{Introduction}

Assessments of how anthropogenic climate change (ACC) may affect the frequency and intensity of hailfall in the future require a careful consideration of a range of physical processes and scales. To begin, one must confront the question of how deep convective stormswhich are the hail generators-are themselves impacted

\footnotetext{
T) Supplemental information related to this paper is available at the Journals Online website: https://doi.org/10.1175/JCLI-D-180740.s1.

${ }^{\text {a }}$ Current affiliation: Cooperative Institute for Mesoscale Meteorological Studies, University of Oklahoma, and NOAA/NWS/ Storm Prediction Center, Norman, Oklahoma.
}

Corresponding author: Robert J. Trapp, jtrapp@illinois.edu by ACC. This has been addressed most broadly by the "environmental" approach (Brooks et al. 2003), which exploits the fact that convective-storm organization and intensity are strongly controlled by ambient (or environmental) profiles in temperature, humidity, and wind within the troposphere. Specific quantifications of these profiles, namely, convective available potential energy (CAPE), and bulk vertical wind shear over the $0-6-\mathrm{km}$ layer (S06), have been coevaluated using global and regional climate model (GCM and RCM) output. Within the United States in particular, CAPE tends to exhibit robust increases over most future time periods and greenhouse gas (GHG) scenarios [e.g., Trapp et al. 2007; Del Genio et al. 2007; Trapp et al. 2009; Diffenbaugh et al. 2013; Gensini et al. 2014; see also the review by Allen (2018)]. This is compelling here because per parcel theory, the theoretical maximum updraft speed $\left(w_{\max }\right)$ is proportional to CAPE via 


$$
w_{\max }=\sqrt{2 \mathrm{CAPE}},
$$

and a basic premise in studies of hail formation is that intense updrafts are required to support the growth of large hailstones with large terminal velocities (Knight and Knight 2001).

Hail formation also depends on vertical wind shear, as has been emphasized recently by Dennis and Kumjian (2017) (but see also, e.g., Nelson 1983; Ziegler et al. 1983; Nelson 1987). The effect of shear on an updraft is to elongate and/or horizontally expand it, thus providing a larger region for hail embryos to develop, and also a larger volume for subsequent hail growth (Dennis and Kumjian 2017). In more general terms, shear also affects the convective morphology, with large S06 ( $\left.220 \mathrm{~m} \mathrm{~s}^{-1}\right)$ favoring a supercellular morphology; in the United States at least, the largest hail is thought to be generated by supercellular thunderstorms (Smith et al. 2012; Blair et al. 2017). Hail generated by less-organized morphologies, including multicellular thunderstorms (Ziegler et al. 1983; Nisi et al. 2016), tends to be smaller (Blair et al. 2017), but the hailstorm development still requires nonnegligible S06. These effects are noteworthy because S06 is generally expected to decrease over most future time periods and GHG scenarios (e.g., Trapp et al. 2007; Trapp et al. 2009), albeit with the caveat that large decreases in S06 tend to occur when CAPE is relatively low (Diffenbaugh et al. 2013).

Surface hailfall ultimately depends on the temperature of the air through which the hailstones fall, as well as the relative humidity of this air: the rate of melting is slower in drier air (Rasmussen and Pruppacher 1982). There is evidence of increasing trends in the height of the melting level (i.e., the height of the $0^{\circ} \mathrm{C}$ isotherm) in the tropics (Bradley et al. 2009), high-mountain Asia (Wang et al. 2014), France (Dessens et al. 2015), and Peru (Schauwecker et al. 2017). GCM projections evaluated at particular locations also suggest future increases in the height of the melting level (Dessens et al. 2015; Schauwecker et al. 2017). It is unclear at this time if compensating effects of lower relative humidity in the boundary layer might offset this trend. Given that projected future storm environments often contain more convective inhibition (Diffenbaugh et al. 2013), they may also contain regions of lower relative humidity.

The environmental-parameter approach has been applied to climate model simulations to make projections of the frequency and intensity of severe convective storms in future climates (e.g., Trapp et al. 2007; Del Genio et al. 2007; Trapp et al. 2009; Diffenbaugh et al. 2013). It is important to note, however, that "severe" is a generic category that (in the United States) includes storms that generate tornadoes, large hail, and/or damaging nontornadic winds. In other words, these projections are not specifically for hail, in part because this approach does not explicitly involve any of the microphysical processes responsible for hail formation and growth.

Toward that end, Brimelow et al. (2017) developed a novel method whereby environmental profiles from coarse (50-km grid lengths) RCMs [via the North American Regional Climate Change Assessment Program (NARCCAP)] were used to drive an offline hail growth model (HAILCAST; Brimelow et al. 2002) and thus predict maximum hail size at individual RCM grid points. The 1D model simulates the growth of hail embryos that are introduced at a thermodynamically deduced cloud base. The amount of growth (hail size) depends on the temperature and supercooled cloud water within each profile, as well as the strength and duration of a steady, adiabatic 1D updraft; the updraft properties are parameterized using CAPE and vertical wind shear. Brimelow et al. (2017) concluded that the frequency of hail, especially of relatively small diameters $(10 \mathrm{~mm})$, will decrease in the late twenty-first century over most of North America. They further concluded that when hail does occur, its maximum size will tend to be larger, suggesting an increase in hail damage potential under ACC.

Their method, and thus conclusions, are not without limitations however. The assumption of updraft steadiness in the HAILCAST model, over a duration derived from a simple product between CAPE and vertical wind shear, likely overestimates hail size. The assumption of updraft existence itself given sufficiently positive parcel buoyancy in a profile (Brimelow et al. 2002) likely overestimates hail frequency. This is underscored by the recent pseudo-global warming (PGW) simulations of Trapp and Hoogewind (2016), who reaffirm that positive buoyancy is necessary but not sufficient: Convection initiation is usually predicated on the existence of sufficient parcel lifting to overcome layers of negative buoyancy [as quantified by convective inhibition (CIN)], and this process is not explicitly treated in HAILCAST.

Indeed, this convection-initiation issue has been a primary motivating factor for implementations of dynamical downscaling at convection-permitting resolutions (e.g., Trapp et al. 2011). The dynamical-downscaling implementations of Leslie et al. (2008) and Mahoney et al. (2012) were specifically focused on hail occurrence. Both used horizontal grid lengths of $\sim 1 \mathrm{~km}$, but over computational domains of limited extent: $\sim 4^{\circ} \times 4^{\circ}$ domain over the Sydney basin in Australia 
(Leslie et al. 2008), and $\sim 6^{\circ} \times 6^{\circ}$ domain over the U.S. state of Colorado (Mahoney et al. 2012). Both also followed an event-based simulation methodology, wherein only select events (individual days) that met some criteria based on coarse-grid output [e.g., extreme rainfall (Mahoney et al. 2012) or moderate-to-large CAPE and vertical wind shear (Leslie et al. 2008)] were then further simulated at high resolution. For example, the Colorado study of Mahoney et al. (2012) considered only 20 events (10 during a historical time period, 10 during a future time period) that occurred during the months of June-August. Thus, both studies were limited by a small sample size and limited spatial extent, and accordingly were insufficient to characterize broad changes in hailfall.

Convection-permitting, dynamically downscaled simulations over the entire year, for 30-yr historical (1971-2000) and future (2071-2100) time slices, and with $4-\mathrm{km}$ grid lengths across the entirety of the contiguous U.S. (CONUS) domain, have recently been presented by Hoogewind et al. (2017). In contrast to Mahoney et al. (2012) as well as other dynamical downscaling studies with limited time slices (e.g., Gensini and Mote 2014; Prein et al. 2017), the 30-yr temporal domains used by Hoogewind et al. (2017) have allowed for quantifications of future changes in the seasonality of severe-thunderstorm occurrence; the CONUS spatial domain has also allowed for quantifications of regional changes in severe-thunderstorm occurrence. Herein, we extend the investigation of Hoogewind et al. (2017), and focus explicitly on the possible future changes in the seasonality and regionality of hazardous hailfall under ACC.

\section{Modeling approach and analysis}

The simulation methodology employed by Hoogewind et al. (2017) can be summarized as follows: the Geophysical Fluid Dynamics Laboratory Climate Model, version 3 (GFDL CM3), contribution to phase 5 of the Coupled Model Intercomparison Project (CMIP5), which was shown by Diffenbaugh et al. (2013) and Seeley and Romps (2015) to yield (historically) simulated convective parameters that compare favorably to reanalyses, has been dynamically downscaled over historical (1971-2000) and future (2071-2100 under RCP8.5) time periods. This was accomplished using the nonhydrostatic "advanced research" core of the Weather Research and Forecasting (WRF) Model, version 3.6 (Skamarock et al. 2008). The computational domain for the WRF simulations has 45 vertical levels, a horizontal grid point spacing of $4 \mathrm{~km}$, and encompasses all of the contiguous United States (see Fig. 1). This single domain can be considered convective-storm

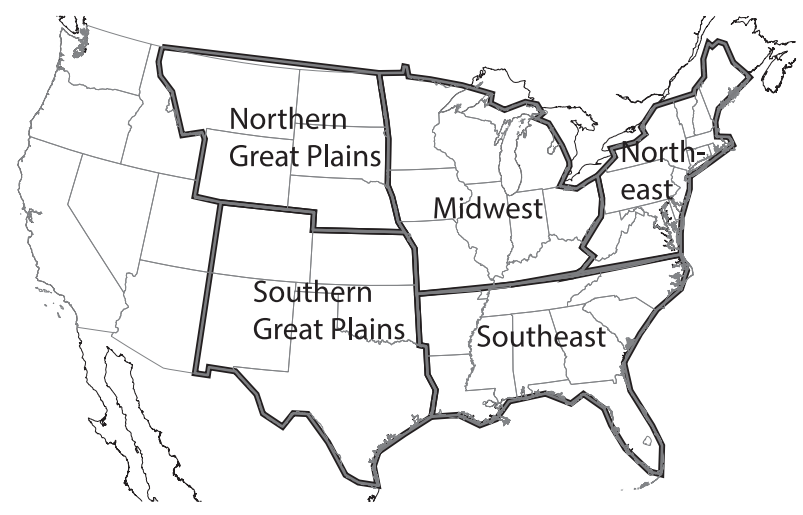

FIG. 1. Computational domain, and subregions discussed in the text: southern Great Plains (SGP), northern Great Plains (NGP), Midwest (MW), Southeast (SE), and Northeast (NE). Adapted from Hoogewind et al. (2017).

permitting, thus precluding the need to parameterize deep moist convection. Necessary parameterizations follow those used in high-resolution WRF Model predictions of convective weather in the United States (Kain et al. 2008) (see also Hoogewind et al. 2017). Of particular relevance to the topic of this research is our use of the Thompson scheme (Thompson et al. 2008) to parameterize cloud microphysical processes. The singlemoment Thompson scheme predicts a single, combined graupel/hail category. The sensitivity of the downscaled results to the use of this particular scheme is explored in the appendix.

The dynamical downscaling procedure is based on Trapp et al. (2011) and involves daily model reinitializations rather than continuous long-term integrations. Specifically, the model is integrated over a 30-h period (0600 UTC day 1 to 1200 UTC day 2), reinitialized, and then integrated/reinitialized over each subsequent 30 -h period. The first $6 \mathrm{~h}$ of each day are used for model "spinup" and discarded, thus leaving daily 24-h (1200-1200 UTC) sequences to be analyzed. This procedure limits error growth, allows for a much more efficient use of computational resources, and does not adversely affect representation of the cycle and evolution of convective precipitation (Trapp et al. 2011). Further discussion of this procedure is provided by Hoogewind et al. (2017), as is an evaluation of simulated rainfall over the historical period.

Hail occurrence is quantified using hourly maximum column-integrated graupel (GRPLmax; $\mathrm{kg} \mathrm{m}^{-2}$ ), which is a run-time diagnostic variable available in WRF version 3.6. Although GRPLmax strictly represents a vertically integrated mixing ratio of the rimed ice category, its use in depicting hail size is heuristically 
established with auxiliary simulations, as described in the appendix. The heuristic analysis yields the following three categories: moderate or greater $(\mathrm{M}+)$ hail, which corresponds approximately to hail diameters $\geq 20 \mathrm{~mm}$, and is assigned at grid points where GRPLmax $\geq$ $10 \mathrm{~kg} \mathrm{~m}^{-2}$; large or greater $(\mathrm{L}+)$ hail, which corresponds approximately to hail diameters $\geq 35 \mathrm{~mm}$, and is assigned at grid points where GRPLmax $\geq 25 \mathrm{~kg} \mathrm{~m}^{-2}$; and very large (VL) hail, which corresponds approximately to hail diameters $\geq 50 \mathrm{~mm}$, and is assigned at grid points where GRPLmax $\geq 50 \mathrm{~kg} \mathrm{~m}^{-2}$.

The categorical hail occurrences are presented via a "hailday" methodology on a coarsened grid. Specifically, an M+, $\mathrm{L}+$, or VL hail day is quantified given at least one exceedance per day of the GRPLmax thresholds within a uniform $1^{\circ} \times 1^{\circ}$ grid, using hourly model output on the native 4-km grid (see Hoogewind et al. 2017). This approach follows from analyses of report-based hail observational data in the United States and is used to reduce spatiotemporal errors that are known to occur in the reports (Doswell et al. 2005; Allen and Tippett 2015). A "convective-storm day," and thus the convective-storm frequency, is likewise quantified given at least one exceedance per day of $40 \mathrm{~dB} Z$ (simulated) radar reflectivity (e.g., Houze et al. 2007) within the $1^{\circ} \times 1^{\circ}$ coarsened grid, using hourly model output on the native 4-km grid.

To show that our coarsened-grid, hail-day methodology is credible, we compare quantifications of hail frequency in the downscaled simulations over the period 1986-2000 to quantifications using observational data over the same period (Fig. 2). The observed annual mean probability (Fig. 2a) is based on the occurrence of at least one (NOAA) report of severe hail per day within a cell on the $1^{\circ} \times 1^{\circ}$ grid; upon averaging the daily probabilities, a Gaussian filter with a spatial smoothing parameter $(\sigma)$ of $1^{\circ}$, or one grid box, is applied. The simulated annual probability (Fig. 2b) is based on the occurrence of $\mathrm{L}+$ hail days from the downscaled simulations. The peak probabilities from the observational analysis are comparable to those from the simulations, but the specific locations of these peaks differ: southern Oklahoma in the observational analysis versus eastern Kansas in the simulations. The simulations also exhibit a much broader area of high probabilities than do the observations. Some of these differences are attributed to biases in the reported hail observations (Allen and Tippett 2015). Nevertheless, the general coverage of the observed and simulated hail-day probabilities exhibit sufficient agreement over the central United States to provide confidence in examining future minus historical differences. Further confidence is provided by the favorable comparison of the modeled distribution to the environmentally derived hail estimates of Allen et al. (2015).
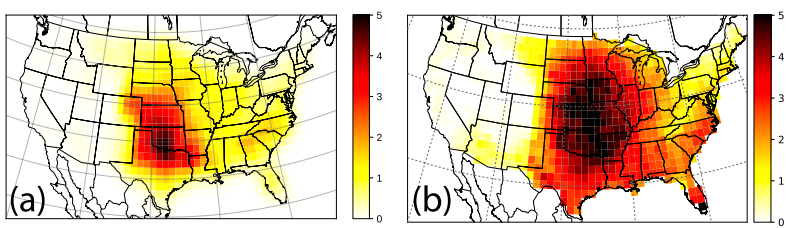

FIG. 2. Annual probability (in percent) of (a) severe hail days, based on hail reports, and (b) $\mathrm{L}+$ hail days, from the historical simulations. Both are based on data from the period 1986-2000, and are analyzed on a $1^{\circ} \times 1^{\circ}$ grid.

\section{Future changes in hail occurrence by estimated hail size}

We begin with differences in monthly hail occurrence between the late twenty-first-century future period and late twentieth-century historical period. Figure 3 indicates statistically significant future increases ${ }^{1}$ in the days with $\mathrm{L}+$ hail for each month of the year over the CONUS (see also Fig. S1 in the online supplemental material). The largest mean increases in $\mathrm{L}+$ hail (of 6 days month ${ }^{-1}$ ) occur in July in the northern Great Plains (see Fig. 1), but mean increases of $\sim 4$ days month ${ }^{-1}$ are found over broad geographical areas during May-August. Statistically significant future increases in the frequency of VL hail days are also projected over the central United States during the spring and summer months (Fig. 4a). The largest mean increases of $\sim 2 \mathrm{VL}$ days month $^{-1}$ again occur in July in the northern Great Plains. Finally, the future frequency of $\mathrm{M}+$ hail days (Fig. 4b) exhibits considerable temporal and geospatial variability. Over roughly the eastern half of the CONUS, statistically significant increases of $\sim 3-5 \mathrm{M}+$ hail days month ${ }^{-1}$ during AprilMay are supplanted by comparable or larger decreases during June-July. Within the western half of the CONUS, and in particular the western portions of the southern and northern Great Plains, increases of more than $6 \mathrm{M}+$ hail days month ${ }^{-1}$ are prominent in JuneAugust. Note that if we exclude days that also had large and/or very large hail, and thus consider only $\mathrm{M}$ rather than M+ hail days (Fig. S2), the geographical areas of frequency increases (decreases) become smaller (larger), but the basic conclusions about this category of hail are the same. Similarly, a consideration of only $L$ days rather than L+ hail days (Fig. S3) reduces (enhances) the

\footnotetext{
${ }^{1}$ In all spatial analyses used in this study, differences between the respective means over the future and historical periods are evaluated locally using a two-tailed $t$ test at a $5 \%$ significance level, with the null hypothesis that the means are the same; field significance is evaluated using the false discovery rate (FDR) methodology (Wilks 2016) with a 5\% global significance level.
} 

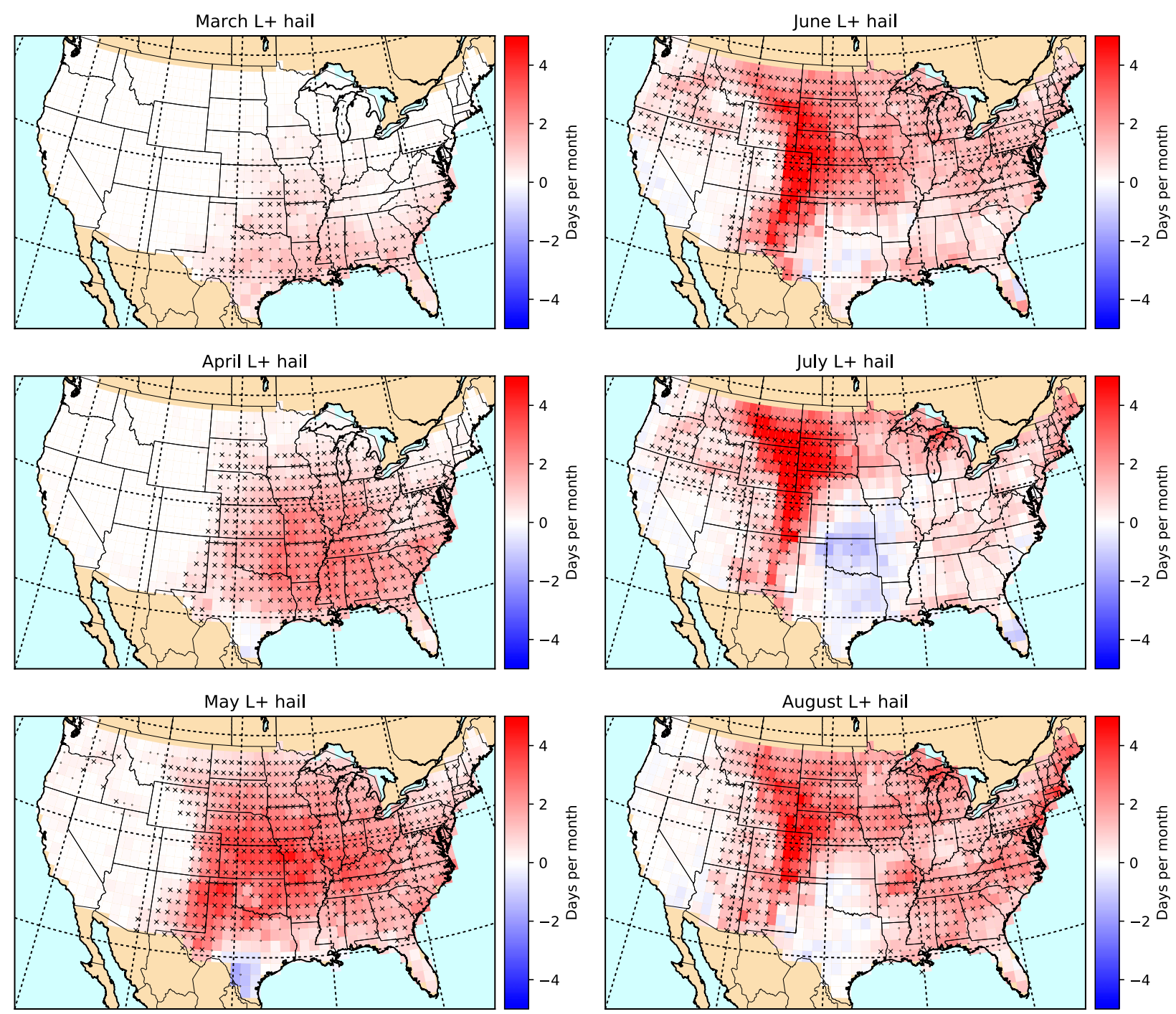

FIG. 3. Change (future minus historical) in mean days per month of large or greater $(\mathrm{L}+$ ) hail. Black dots (black $\times \mathrm{s})$ show locations where the local (global) hypotheses identical means are rejected at the 0.05 level, as determined via a two-sided $t$ test.

geographical areas of frequency increases (decreases), but does not change the basic conclusions about this category of hail.

As can be inferred from Figs. 3 and 4, the mean annual cycles of hail days for our three categories exhibit enhanced future probabilities of hail across the CONUS, throughout the year (Fig. 5a). Consistent with Brimelow et al. (2017), the largest increase is in the VL hail category (Fig. 5a, third column), with a mean peak historical probability of 0.52 in mid-July increasing to a mean peak future probability of 0.90 in late July. We note here that the mid-July peak in VL hail is later in comparison to the early-June peak in observed 5-cm hail occurrence (Allen and Tippett 2015). This is perhaps explained by the dominance of the northern Great Plains contribution to the VL hail cycle; the observed hail occurrence in the northern Great Plains exhibits a mid-July peak. The broader peak in the $\mathrm{L}+$ hail cycle is well in line with that for all observed hail.

The enhanced future probabilities suggest a future lengthening of the "hail season." This can be quantified in terms of total cumulative hail days over the year, which show a 7\%, $21 \%$, and $146 \%$ increase, respectively, in the mean number of future $\mathrm{M}+, \mathrm{L}+$, and VL hail days across the CONUS (Fig. 6). Part of the lengthening owes to an earlier start to the season. Here we adapt the method of Brooks et al. (2014) and consider the nominal start of the season to be the date on which $10 \%$ of the mean annual cumulative grid 
(a)
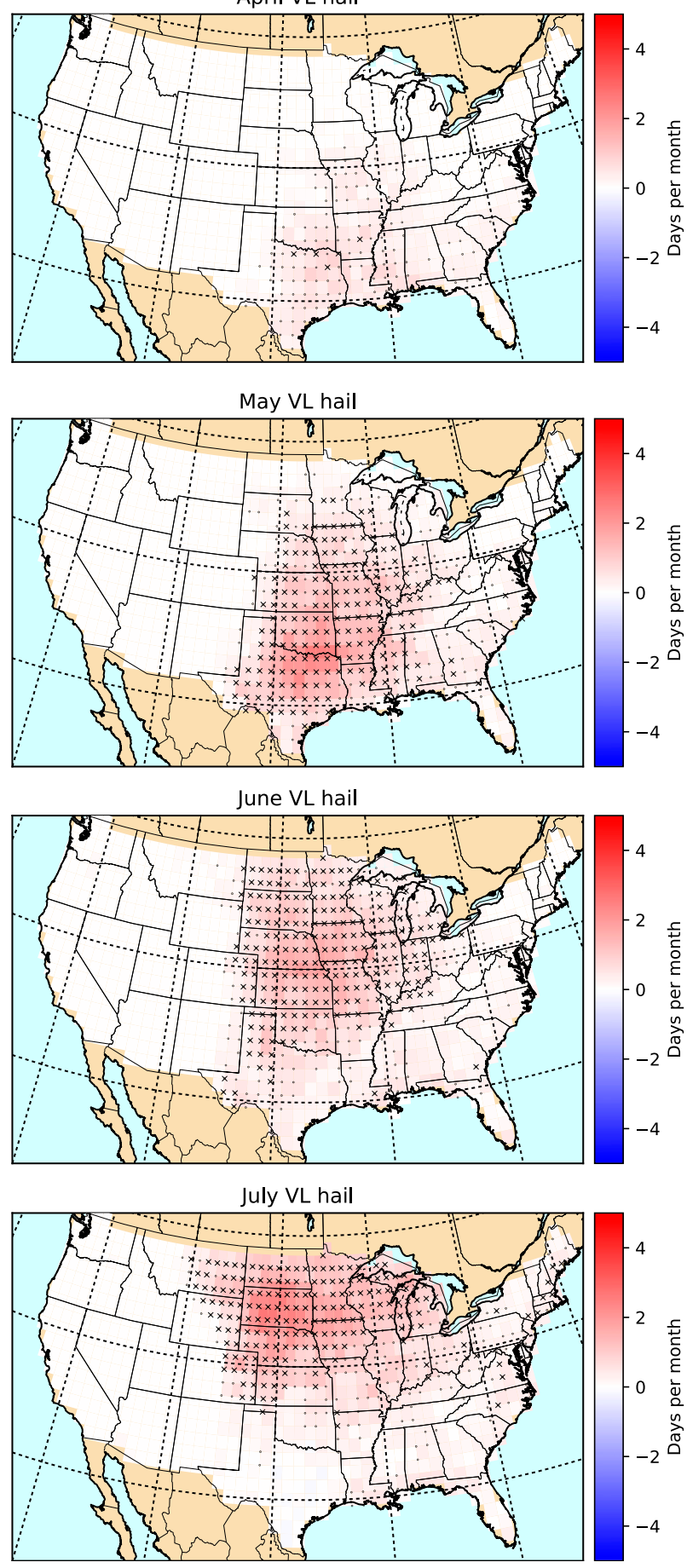

(b)
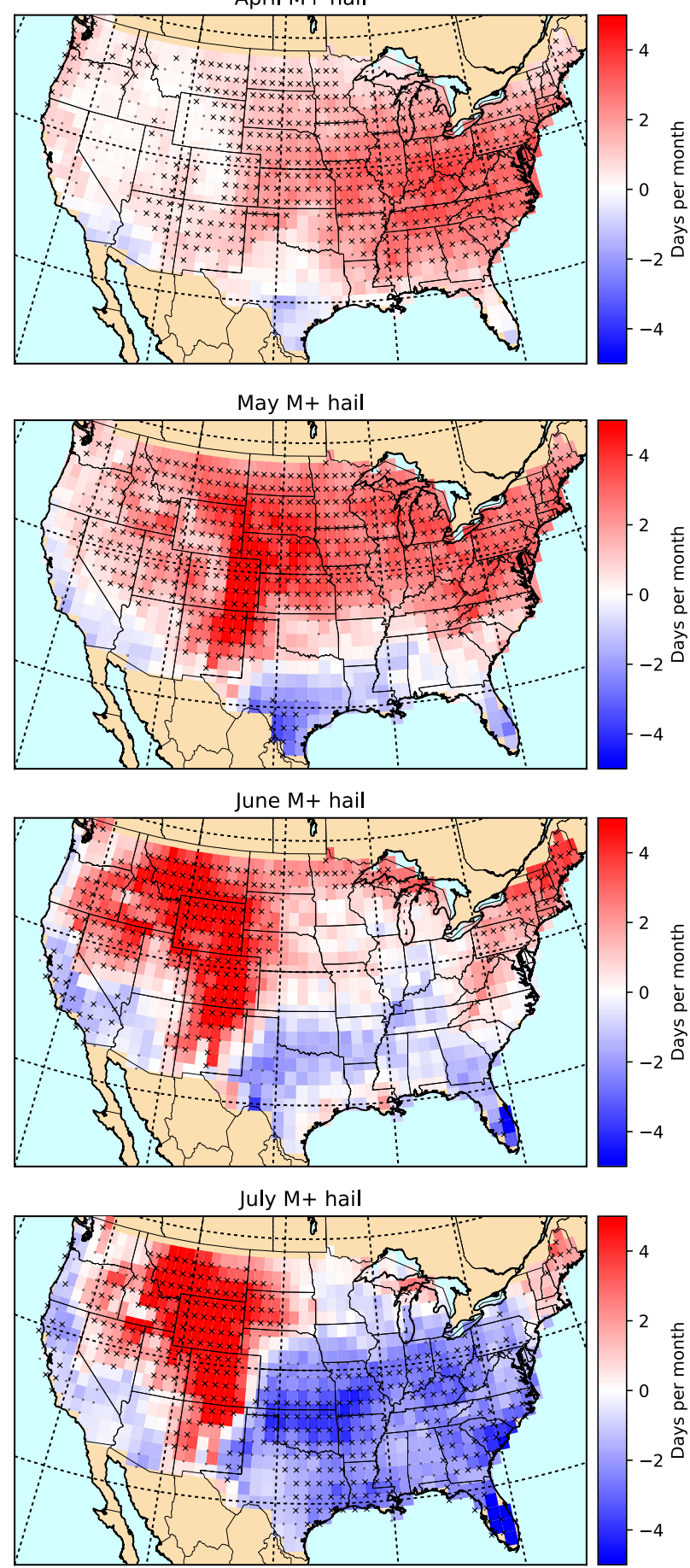

FIG. 4. As in Fig. 3, but for (a) very large (VL) hail and (b) moderate or greater $(\mathrm{M}+)$ hail.

points (a proxy for mean total annual reports) is attained (see Fig. 5b). By this method we find a 16-, 9-, and 9-day earlier start to the $\mathrm{M}+, \mathrm{L}+$, and $\mathrm{VL}$ hail seasons, respectively, under ACC (Fig. 5b). There is significant regional variation to these cumulative days and grid points, but over all regions, the total numbers of cumulative days, and of cumulative grid points, exhibit increases in the future (Table 1). 

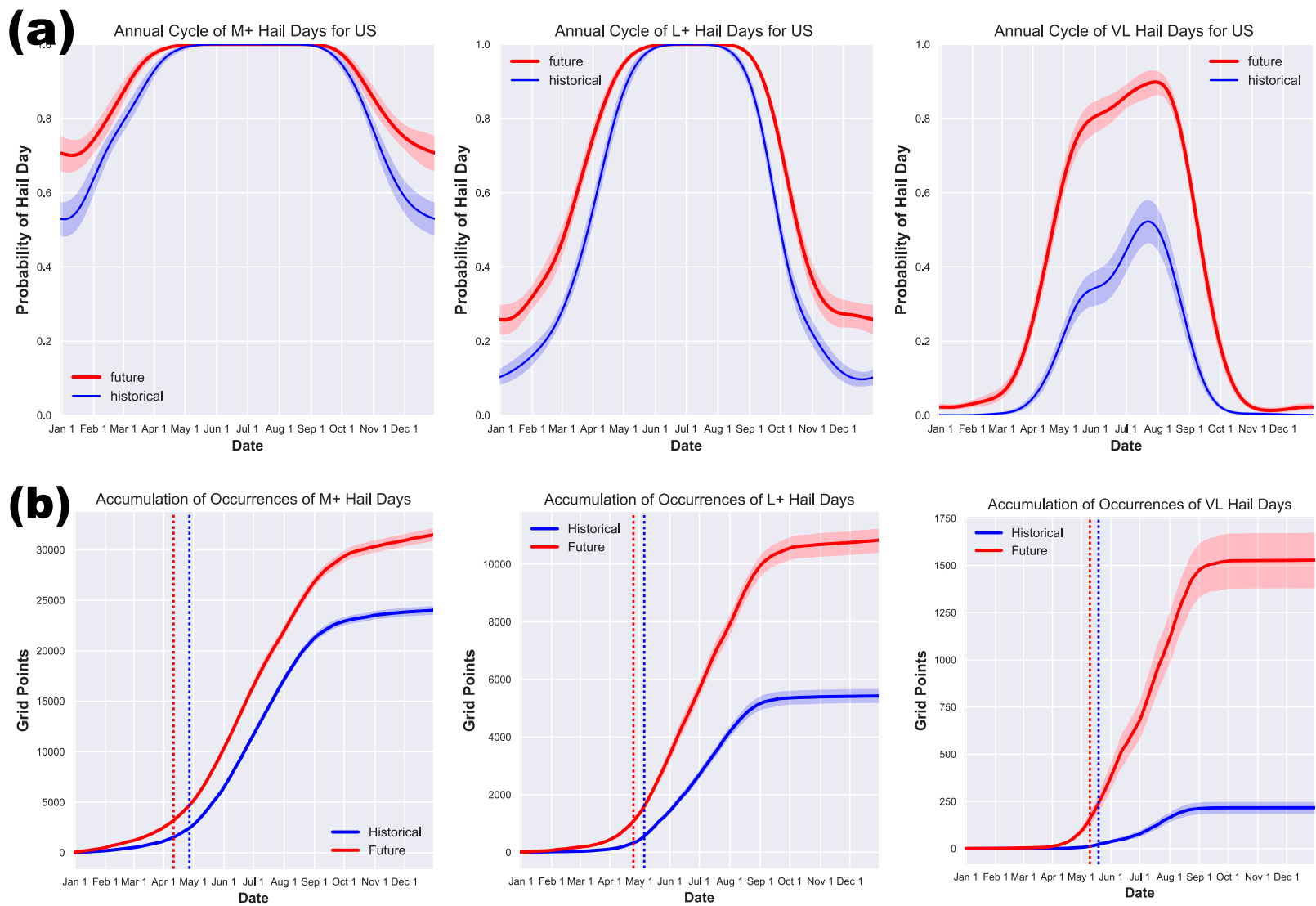

FIG. 5. (a) Mean annual cycle of hail-day probability for $\mathrm{M}+, \mathrm{L}+$, and $\mathrm{VL}$ hail. (b) Mean accumulation of gridpoint occurrences of daily $\mathrm{M}+, \mathrm{L}+$, and VL hail. Both apply to CONUS. Shading represents $95 \%$ CI from 10000 bootstrapped resamples. Blue (red) vertical lines in (b) indicate the mean starting date of the hail season for the historical (future) period.

Unsurprisingly, the annual cumulative hail days comprising the 30-yr means in Fig. 5a exhibit interannual variability. A subjective assessment of the time series of annual hail days over the CONUS (Fig. 7) suggests that the interannual variability over the future period is larger than that over the historical period series, perhaps consistent with the documented variability in precipitation in general (e.g., Pendergrass et al. 2017). Following Tippett (2014) we quantify the variability in terms of a volatility, which is the standard deviation of
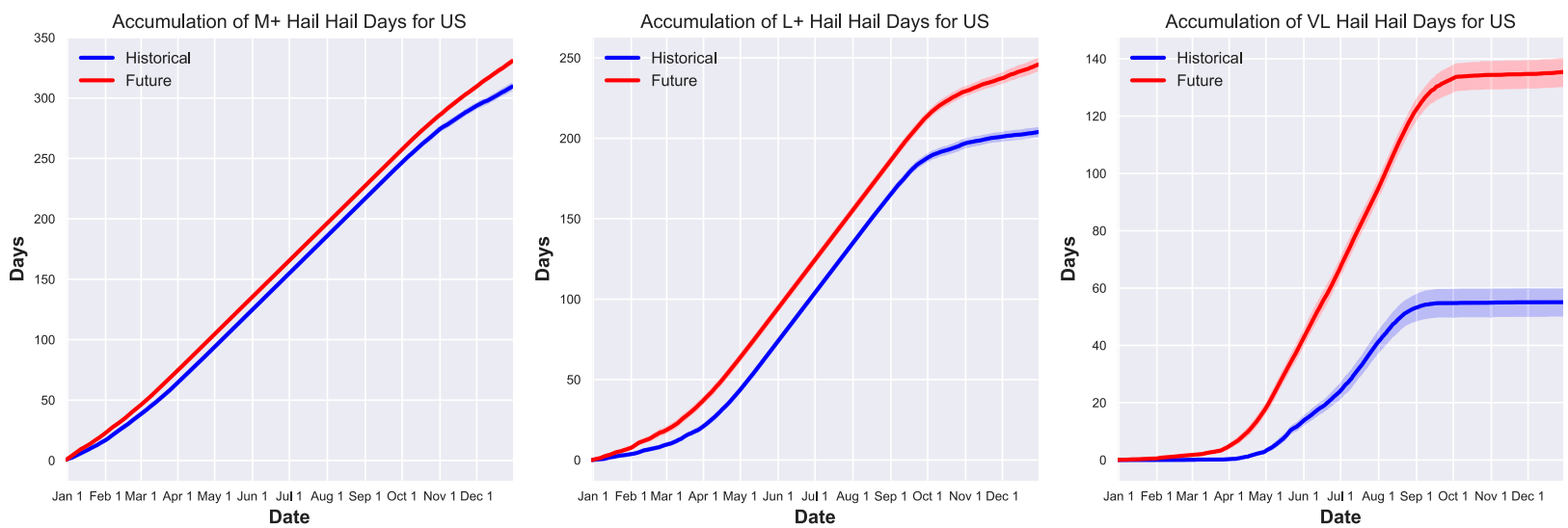

FIG. 6. Mean accumulation of hail days over the year, for $\mathrm{M}+, \mathrm{L}+$, and VL hail across the CONUS. Shading represents $95 \%$ CI from 10000 bootstrapped resamples. 
TABLE 1. Percentage future changes in cumulative days, and cumulative daily grid points, of $\mathrm{M}+, \mathrm{L}+$, and VL hail, for the CONUS, as well as for the SGP, NGP, MW, SE, and NE regions (see Fig. 1).

\begin{tabular}{|c|c|c|c|c|c|c|}
\hline Region & M+ days & $\mathrm{L}+$ days & VL days & $\mathrm{M}+$ points & $\mathrm{L}+$ points & VL points \\
\hline CONUS & $7 \%$ & $21 \%$ & $146 \%$ & $31 \%$ & $100 \%$ & $605 \%$ \\
\hline SGP & $8 \%$ & $21 \%$ & $184 \%$ & $21 \%$ & $71 \%$ & $476 \%$ \\
\hline NGP & $27 \%$ & $49 \%$ & $302 \%$ & $73 \%$ & $157 \%$ & $882 \%$ \\
\hline MW & $20 \%$ & $37 \%$ & $185 \%$ & $26 \%$ & $85 \%$ & $476 \%$ \\
\hline SE & $5 \%$ & $25 \%$ & $311 \%$ & $11 \%$ & $86 \%$ & $812 \%$ \\
\hline $\mathrm{NE}$ & $37 \%$ & $84 \%$ & $828 \%$ & $53 \%$ & $178 \%$ & $1628 \%$ \\
\hline
\end{tabular}

the difference $D$ between the number $N$ of hail days in consecutive years $(i)$ :

$$
D_{i}=N_{i}-N_{i-1}
$$

The volatility over the historical and future periods are 10.6 and 16.6 days, respectively. Although failing an $f$ test for statistical significance, the volatility over the future period is nonetheless larger than that over the historical period. An evaluation of the geospatial volatility difference shows mostly future increases of a few days, with isolated decreases of $\sim 1$ day over southern and northern Great Plains (Fig. S4). We conclude that the annual volatility of $\mathrm{L}+$ hail generally increases in the future, and that this increase appears to be spread over the CONUS.

\section{Possible physical mechanisms}

Although the physical mechanism(s) for the increase in the hail-day variability and volatility under ACC is

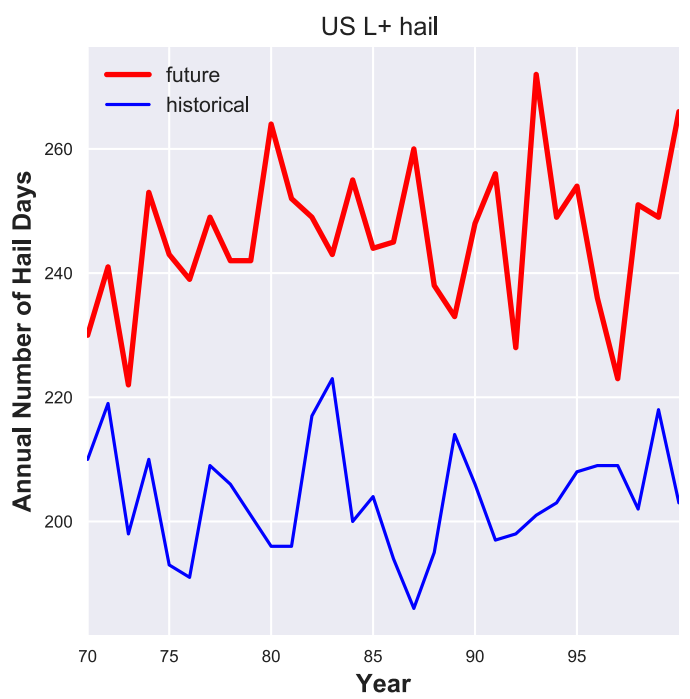

FIG. 7. Time series of annual number of $L+$ hail days over the CONUS, during future and historical periods. unclear (as is also the mechanism for tornado volatility; Tippett 2014), we can offer possible physical explanations for the changes in the hail-day means with the dynamical downscaling approach. Consider first the pronounced decreases in $\mathrm{M}+($ and $\mathrm{M})$ frequency, especially over the eastern half of the CONUS (Figs. $4 \mathrm{~b}$ and S2). As noted in section 1, the argument often invoked to explain such a reduction in hailfallespecially of relatively small hail-under ACC is that an increase in the height of the melting level would allow for a deeper layer for potential melting of falling hailstones (see also Zou et al. 2018). Although the extent of melting also depends on the environmental humidity (Rasmussen and Pruppacher 1982), here we analyze only the environmental temperature. Figure 8 shows that the mean melting-level height in our downscaling simulations ${ }^{2}$ does indeed increase in the future over the CONUS, albeit with geographical and seasonal variations. However, as evidenced by the lack of a geospatial relationship between the fields in Fig. 4b (see also Fig. S2) and Fig. 8, it does not appear that increases in melting-level height have a significant impact on the decreases in $\mathrm{M}+($ and $\mathrm{M}$ ) hail, nor on changes in $\mathrm{L}+$ and VL hail. Geospatially, the melting-level increases and $\mathrm{M}+($ and $\mathrm{M})$ hail decreases also do not correspond well to increases in rainfall frequency, as would be expected if enhanced hail melting occurs (Fig. 9; see also Fig. S5). To address the possibility that the mean melting-level height changes might not be representative of changes on days when the hail occurs, we have also constructed 2D histograms of melting level height

\footnotetext{
${ }^{2}$ The melting level (height of $0^{\circ} \mathrm{C}$ ) in each grid column is determined via linear interpolation of the two model heights (mean sea level) where temperature is above and below $0^{\circ} \mathrm{C}$. For our spatial analyses, we used the melting level at 1800 UTC. This particular time was chosen because it typically precedes the initiation of deep convection, thus allowing us to mitigate the effects of ongoing convective storms on the vertical temperature profile; the basic conclusions about the effects of melting level are, however, relatively insensitive to the specific time of analysis, provided that it is within the 3-6h after local sunrise.
} 

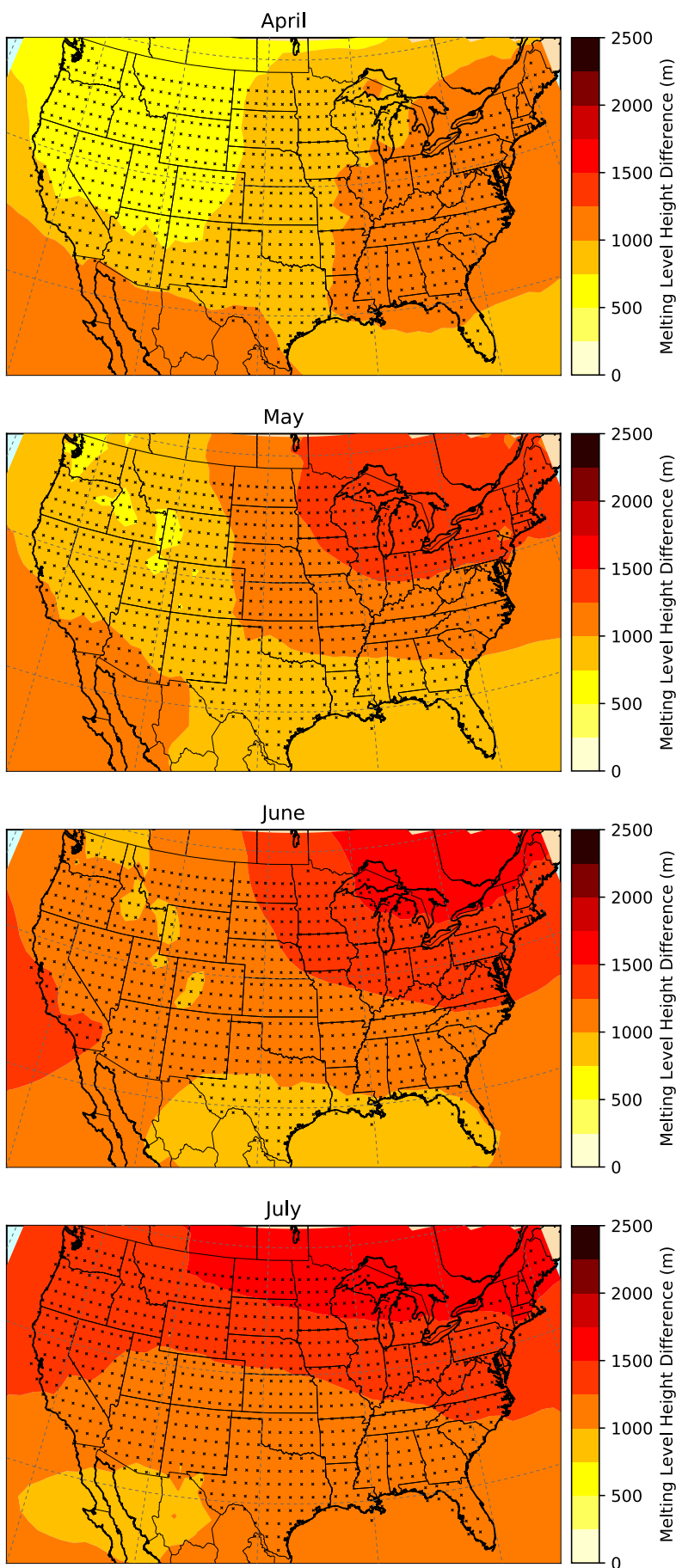

FIG. 8. Mean change (future minus historical) in the height $(\mathrm{m})$ of the melting level $\left(0^{\circ} \mathrm{C}\right)$.

versus mixed-layer (ML) CAPE (Fig. 10). These histograms clearly indicate that the changes in melting level height shown in Fig. 8 do not depend on changes in MLCAPE. In other words, the melting level height of an intense convection/hailstorm environment is well
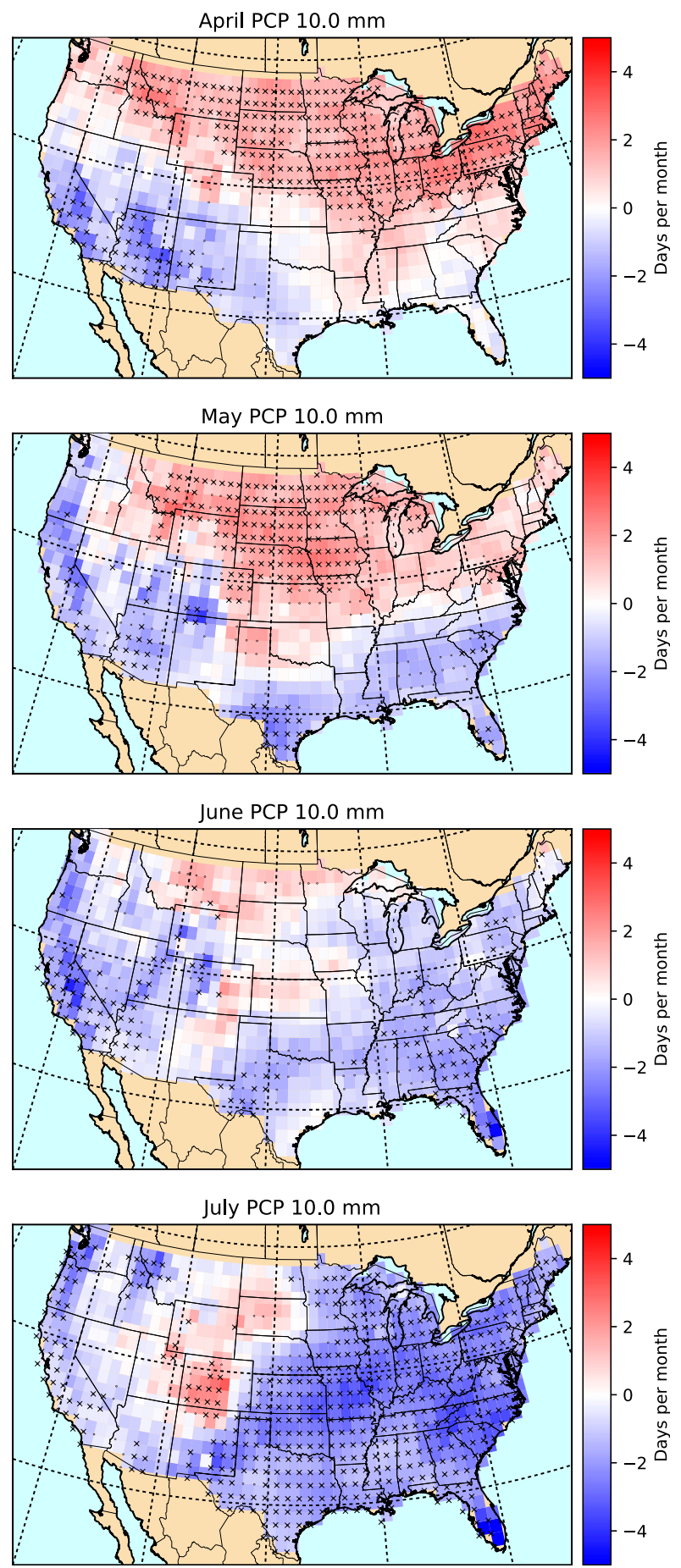

FIG. 9. As in Fig. 3, but for mean days per month of daily precipitation exceeding $10 \mathrm{~mm}$.

represented by the melting level height across all environments, and accordingly, the mean melting level changes portrayed in Fig. 8 should also be valid on days of hail occurrence. We conclude therefore that, although the melting level height increases might explain 

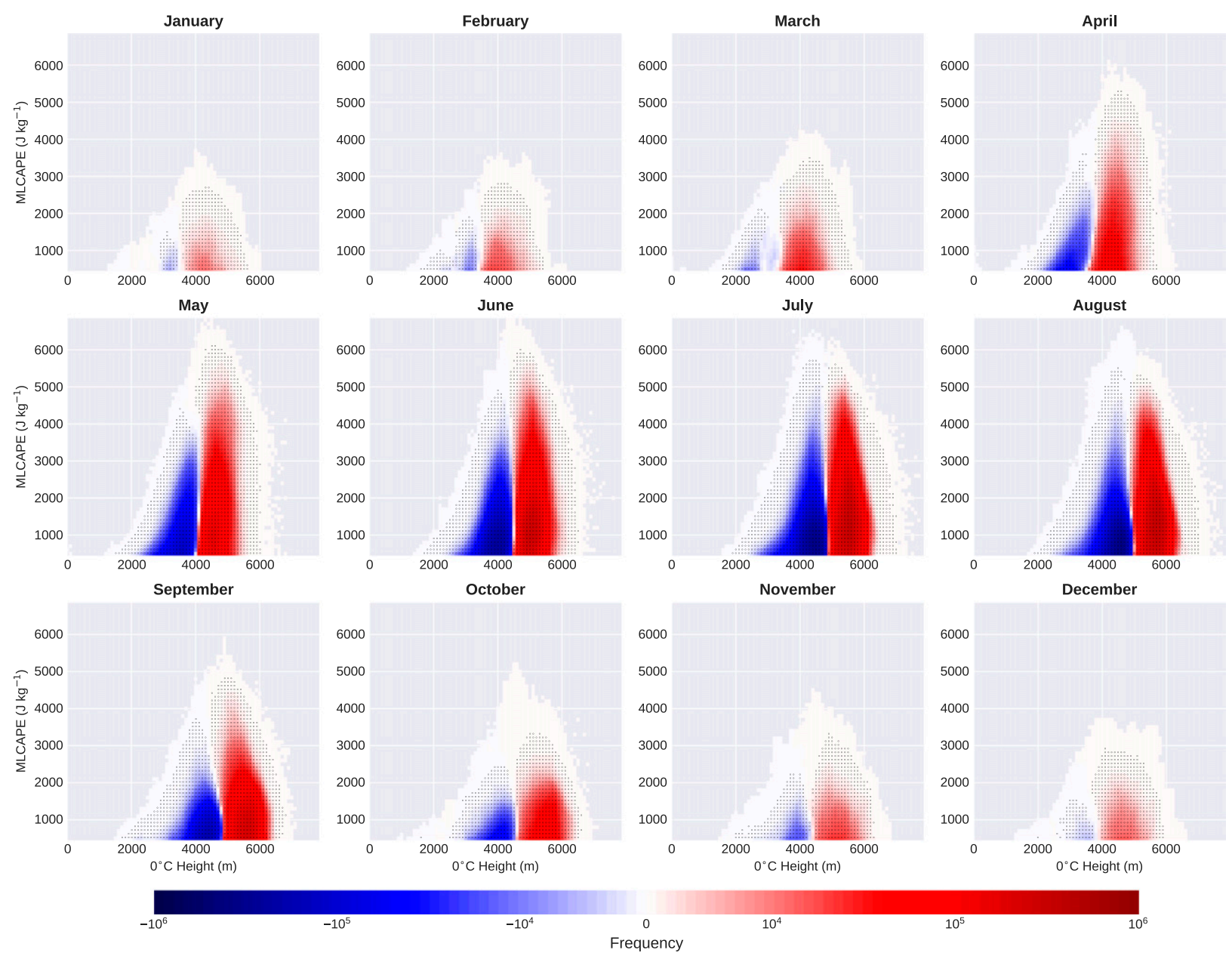

FIG. 10. 2D histograms of MLCAPE vs melting level, which are constructed using data from every grid point east of longitude $105^{\circ} \mathrm{W}$ where MLCAPE exceeds $500 \mathrm{~J} \mathrm{~kg}^{-1}$. The histograms specifically are differences (future minus historical) in the joint frequencies of MLCAPE and melting level. Stippling indicates where the monthly distributions are statistically significantly different from one another at the $95 \%$ confidence level using the Wilcoxon rank-sum test.

reductions in small hail and perhaps in $\mathrm{M}$ hail in some regions of the United States, they do not appear to explain well the specific reductions in $\mathrm{M}$ (and $\mathrm{M}+$ ) hail throughout parts of the Midwest and eastern United States.

Noting that hail generation first requires the existence of a convective storm, it is possible that some of the reduction in $\mathrm{M}$ (and $\mathrm{M}+$ ) hail is due to a reduction in convective storm frequency itself. Storm (or more precisely, convective core) frequency can be represented explicitly in our simulations using daily grid point occurrences of $40 \mathrm{dBZ}$ (simulated) radar reflectivity (e.g., Houze et al. 2007). We find that convective storm frequency decreases generally throughout the CONUS during the summer months (Fig. 11). This less frequent convection initiation is consistent with the projected increases in CIN (Hoogewind et al. 2017), although $\mathrm{CIN}$ alone is not a perfect predictor of initiation (Trapp and
Hoogewind 2016). It is also consistent with a reduced frequency of rainfall in summer (e.g., Fig. 9); that is, decreases (increases) in rainfall frequency are mostly a manifestation of decreases (increases) in convective-storm frequency. (Some realization of this relationship is already appearing in the observational data; see Trapp and Hoogewind 2018). Thus, we conclude that over the CONUS, the reduction in $\mathrm{M}$ and $\mathrm{M}+$ hail owes at least in part to a reduction in the initiation of deep convective storms.

Now we consider possible physical explanations for increases in L+ and VL hail frequency (e.g., Figs. 3 and 4). As noted already, projected increases in CAPE suggest an increase in updraft intensity that in turn would support (but of course, not guarantee; e.g., see Kumjian et al. 2019) the growth of larger hailstones. Although updrafts under future climates fall short of the $w_{\max }=\sqrt{2 \mathrm{CAPE}}$ prediction (Trapp and Hoogewind 

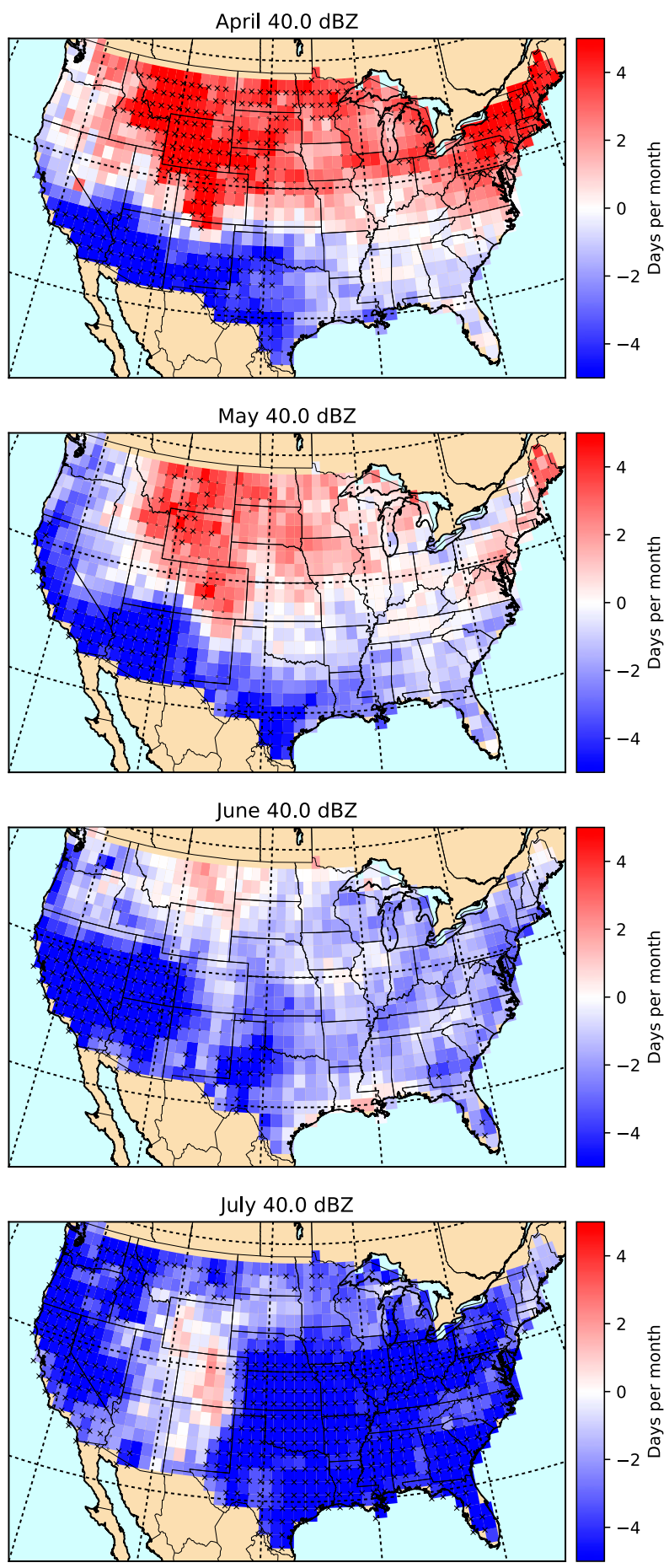

FIG. 11. As in Fig. 3, but for mean days per month of deepconvective core occurrence, based on existence of $40 \mathrm{~dB} Z$ simulated radar reflectivity factor at a height of $1 \mathrm{~km}$ AGL.

2016), Hoogewind et al. (2017) have indeed demonstrated a higher future occurrence of more intense updrafts in these simulations. Higher CAPE also supports wider updrafts, as does stronger vertical wind shear (e.g.,
Marion and Trapp 2019): both environmental changes would provide a larger region for hail embryos, and also a larger volume for subsequent hail growth (e.g., Dennis and Kumjian 2017). To assess whether updraft sizes exhibit future increases given the projected increases (decreases) in CAPE (S06), and then to assess whether the size changes could help explain the higher frequency of L+ and VL hail, we have explicitly computed the size of all updraft cores in the high-resolution simulations. ${ }^{3}$ We find that updrafts are relatively wider in the future, and that the population fraction of these large updrafts increases into the warm season (Figs. S6S8). If we require that the updrafts contain $\mathrm{M}+$ hail, we additionally find that hail-generating updrafts are also relatively wider (and more numerous) in the future (Fig. 12). It is possible that such wider updrafts could be indicative of multicellular storms or mesoscale convective systems, which are less likely to generate large hail; it is also not a necessary condition for large-hail generation that the updraft be wide. With these caveats, we conclude that the environmental changes under ACC allow for future convective updrafts that are wider and more intense, and thus provide favorable conditions for the growth of more L+ and VL hail.

\section{Summary and conclusions}

Herein we used an unprecedented set of convectionpermitting, dynamically downscaled simulations over the entire year, from 30-yr historical (1971-2000) and future (2071-2100) time slices, and with 4-km grid lengths across the entirety of the CONUS domain, to investigate possible changes in the seasonality and regionality of hazardous hailfall under ACC. These simulations indicate that future hail seasons in the United States may begin earlier in the year, be slightly longer, and exhibit more interannual variability. The simulations also indicate that such changes are distributed over broad geographical areas, with details that depend on hail size. In particular, future increases in the frequency of large hail $(\geq 35$ - $\mathrm{mm}$ diameter) are depicted over much the CONUS, during all four seasons; the largest increases occur during July and within the northern Great Plains. Future increases in very large hail ( $\gtrsim 50$-mm diameter) occur mostly during

\footnotetext{
${ }^{3}$ Updraft area is determined from the hourly vertical velocity at the $500-\mathrm{hPa}$ level, on the native $(4 \mathrm{~km})$ grid. We chose $500 \mathrm{hPa}$ because it reasonably represents the midlevel of most deep convective storms across the CONUS. The area itself is given as the number of contiguous grid points where the vertical velocity exceeds a threshold, here chosen to be $10 \mathrm{~m} \mathrm{~s}^{-1}$. The basic conclusions drawn from updraft area based on a 10 or $20 \mathrm{~m} \mathrm{~s}^{-1}$ threshold are the same.
} 

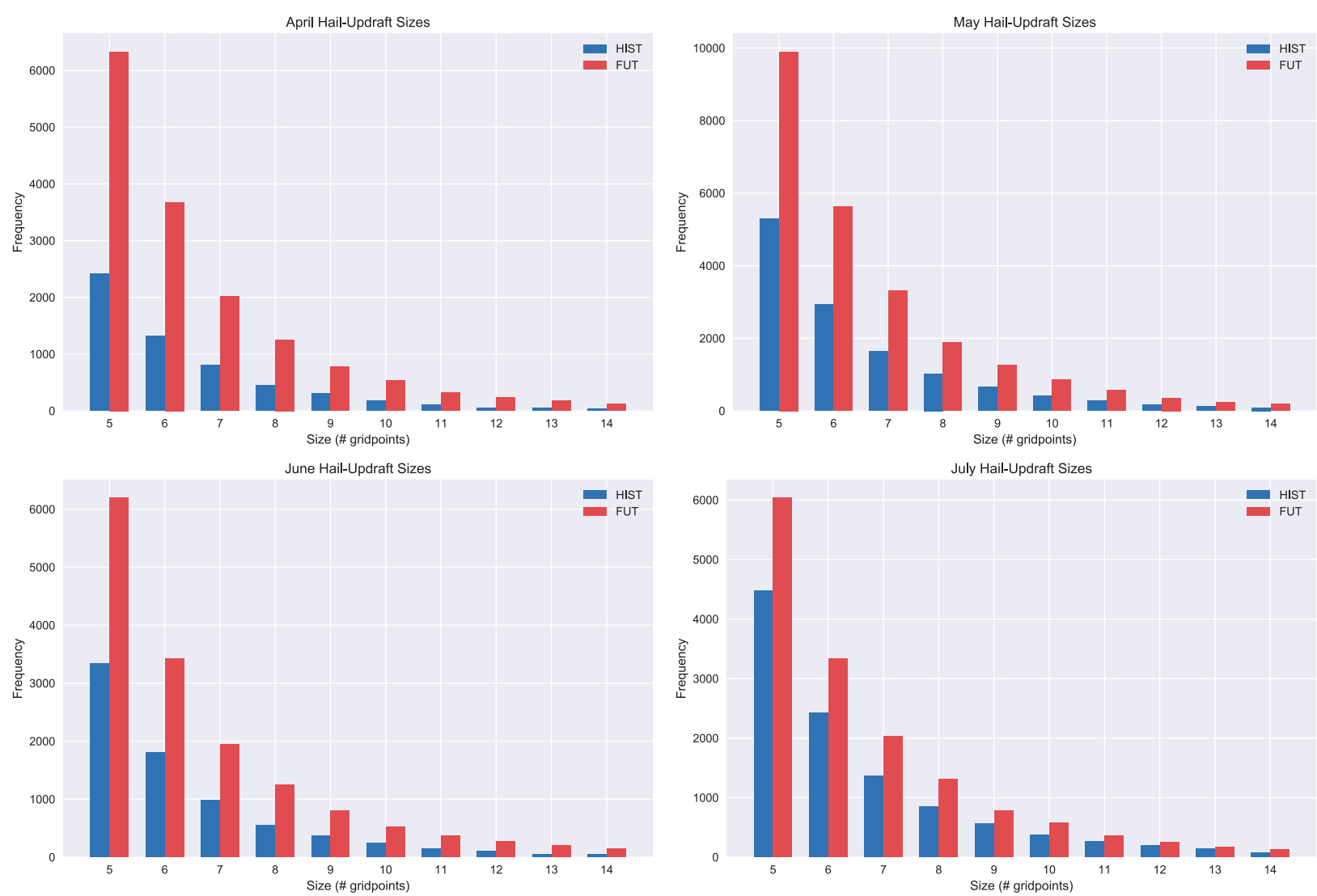

FIG. 12. Group bar chart of hail-generating updraft sizes over the historical (HIST) and future (FUT) time periods. Here, size is given in terms of number of contiguous grid points where both the $\mathrm{M}+$ hail criterion is satisfied and $w \geq 10 \mathrm{~m} \mathrm{~s}{ }^{-1}$ at the 500 hPa level.

boreal spring and summer within the central United States. And, although future increases in moderate hail ( $\gtrsim 20$-mm diameter) are indicated throughout the year, future decreases occur over much of the eastern United States in summer. Such decreases appear to be due primarily to a decrease in convective-storm frequency. To summarize, the indication during summer is of fewer overall days of convective storms and thus fewer hailstorm days, but of larger hail on days when convective storms do occur; the indication during spring is of more days overall of convective storms, and of more days of moderate, large, and very large hail.

This hail-hazard scenario emerging from the convectionpermitting dynamical downscaling is, in essence, consistent with what can be inferred from studies relying only on environmental proxies derived from RCM and GCM simulations [e.g., see the review by Allen (2018)]. However, the lack of explicit control of convective-storm occurrence in these studies likely introduces nonuniform biases to the inferred hail frequency (Hoogewind et al. 2017). A similar statement can be made about the hail frequencies determined by Brimelow et al. (2017), who employed a novel hail growth model, but still parameterized updraft occurrence using environmental information supplied by NARCCAP.

Our conclusions are not without limitation, however. For example, they are based on a single model realization (i.e., a single GCM driver and a single set of model physical parameterizations, which includes a single-moment microphysical scheme with a single rimed hydrometeor category). This is the compromise made for the sake of high (convection-permitting) resolution (see also Gensini and Mote 2015; Prein et al. 2017). Some testing (see the appendix) shows that our overall results do not appear to depend heavily on the choice of microphysical parameterization (although further investigation is needed with double-moment schemes that explicitly predict separate graupel and hail categories). Nevertheless, we lack the ability to quantify the uncertainty that is afforded with an ensemble of coarse-resolution GCMs or RCMs. On the other hand, such coarser-resolution (non-convection-permitting) simulations, and approaches that explicitly use their data, lack the ability 
to confidently quantify convective storm frequency, which we show is a key limiter in hail frequency. The possibility that convective and microphysical processes that are poorly resolved here could also contribute to changes in hail frequency awaits future work with much finer grids.

Such finer grids will also be necessary to address changes in hail swaths and hail accumulations from individual storms under ACC. One of our hypotheses is that hail swaths will be relatively wider in the future, as might be expected given increases in the area of hailgenerating updrafts (Fig. 11). While traditional dynamical downscaling could be an appropriate means of addressing this and other hypotheses, we have chosen instead to pursue event-level PGW applications (e.g., Trapp and Hoogewind 2016), which allows for detailed analyses of individual storm characteristics. This work is ongoing, and will be described in a future publication.

Acknowledgments. We acknowledge the three anonymous reviewers for providing comments and suggestions that helped improve this paper, and Dr. Rebecca Adams-Selin for providing the WRF-HAILCAST code used in establishing the hail-category methodology. We also acknowledge the Rosen Center for Advanced Computing at Purdue University for providing computational resources for the downscaling simulations, and Prof. Michael Baldwin at Purdue University for his role in facilitating the simulations. The Purdue Climate Change Research Center provided partial financial support for K.A.H. while she was a student at Purdue University. The downscaling project itself was initiated with support from the National Science Foundation under Grant NSF ATM 0541491. Model data were analyzed using resources from the Blue Waters sustainedpetascale computing project, which is supported by the National Science Foundation and the State of Illinois.

\section{APPENDIX}

\section{Quantification of Hail Occurrence with a Bulk Microphysical Scheme}

The top 10 daily occurrences of large GRPLmax values $\left(\geq 25 \mathrm{~kg} \mathrm{~m}^{-2}\right)$ over all days within the 30 -yr historical and 30-yr future periods were identified in the downscaling simulations. Each of these 20 days was then resimulated using a more recent version (3.8) of WRF, to take advantage of the inline version of HAILCAST (i.e., WRF-HAILCAST; Adams-Selin and Ziegler 2016) and its predictions of maximum and average hail diameter at the ground (HCASTmax and HCASTavg, respectively); we essentially used these
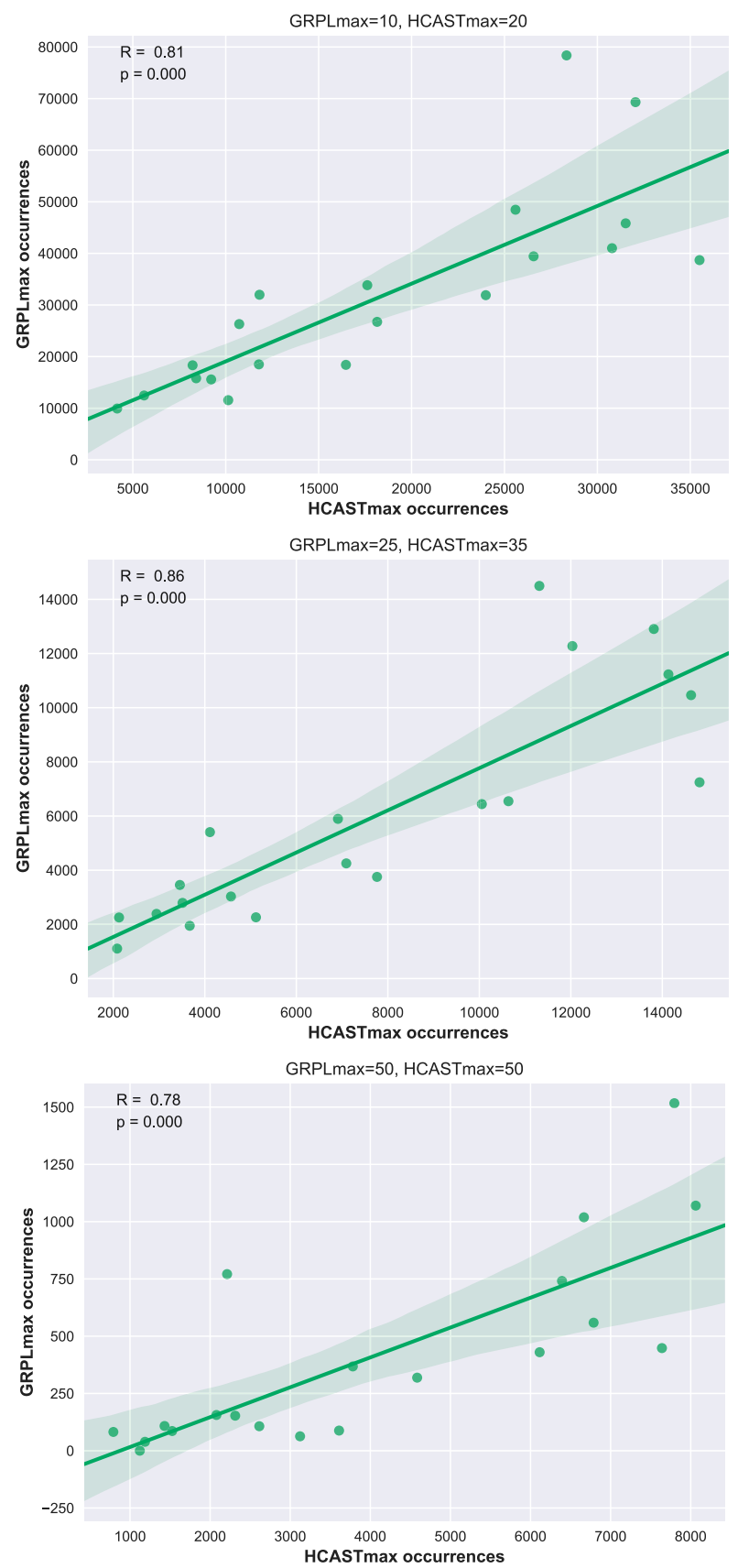

FIG. A1. Scatterplot of GRPLmax vs HCASTmax across the 20 auxiliary simulations, for three pairs of variable thresholds: GRPLmax $\geq 10 \mathrm{~kg} \mathrm{~m}^{-2}$ and HCASTmax $\geq 20 \mathrm{~mm}$, GRPLmax $\geq$ $25 \mathrm{~kg} \mathrm{~m}^{-2}$ and HCASTmax $\geq 35 \mathrm{~mm}$, and GRPLmax $\geq 50 \mathrm{~kg} \mathrm{~m}^{-2}$ and HCASTmax $\geq 50 \mathrm{~mm}$.

variables as "truth" in the 20 auxiliary simulations, with the acknowledgment that the predicted hail diameters from WRF-HAILCAST have varying degrees of accuracy as compared to observations (Adams-Selin et al. 2019). We then evaluated daily occurrences based on a range of thresholds of GRPLmax as well as 

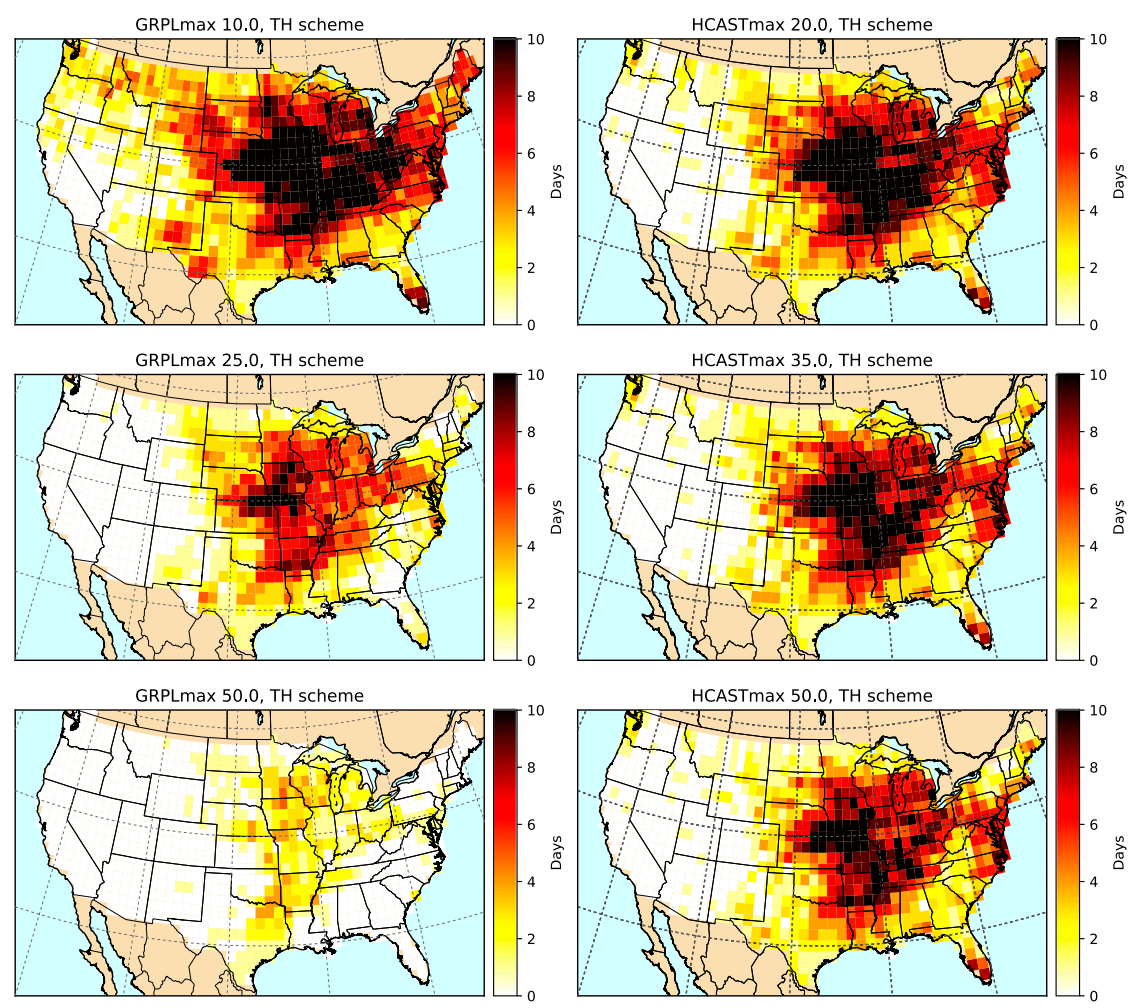

FIG. A2. Spatial occurrences (days) where the respective GRPLmax and HCASTmax thresholds are met: GRPLmax $\geq 10 \mathrm{~kg} \mathrm{~m}^{-2}$, GRPLmax $\geq 25 \mathrm{~kg} \mathrm{~m}^{-2}$, and GRPLmax $\geq$ $50 \mathrm{~kg} \mathrm{~m}^{-2}$; and HCASTmax $\geq 20 \mathrm{~mm}$, HCASTmax $\geq 35 \mathrm{~mm}$, and HCASTmax $\geq 50 \mathrm{~mm}$.

HCASTmax, and found pairs of GRPLmax and HCASTmax occurrences that exhibited the largest linear correlation and were closest to one-to-one.

Figure A1 demonstrates high and statistically significant (at the $p=0.05$ level) correlations between grid point occurrences of GRPLmax and HCASTmax (as well as of HCASTavg), across all 20 auxiliary simulations, for the following three pairs of variable thresholds: GRPLmax $\geq 10 \mathrm{~kg} \mathrm{~m}^{-2}$ and HCASTmax $\geq 20 \mathrm{~mm}$, GRPLmax $\geq 25 \mathrm{~kg} \mathrm{~m}^{-2}$ and HCASTmax $\geq 35 \mathrm{~mm}$, and GRPLmax $\geq 50 \mathrm{~kg} \mathrm{~m}^{-2}$ and HCASTmax $\geq 50 \mathrm{~mm}$. The values of these HCASTmax thresholds (and thus their GRPLmax counterparts) are used to define the categories of moderate or greater $(\mathrm{M}+)$ hail, large or greater $(\mathrm{L}+)$ hail, and very large $(\mathrm{VL})$ hail.

The spatial locations for these respective occurrences in the 20 simulations are shown in Fig. A2 and generally support our usage of GRPLmax from the Thompson scheme, especially for the $\mathrm{M}+$ and $\mathrm{L}+$ hail categories. For the VL hail, the magnitude of HCASTmax $\geq 50 \mathrm{~mm}$ occurrences is clearly much higher than the corresponding GRPLmax $\geq 50 \mathrm{~kg} \mathrm{~m}^{-2}$ occurrences. We attribute this magnitude mismatch to the fact that in WRFHAILCAST, the growing hailstones accrete all available supercooled liquid water, without consideration of its depletion by entrainment or other precipitation, implying that the predicted sizes are upper limits (and may in some cases be overestimates).

To address concerns that, as a vertically integrated quantity, GRPLmax may be representing graupel/hail aloft rather than at the surface, we compared fields of graupel/hail mixing ratio at the lowest model level to the fields of GRPLmax and also HCASTmax. A representative example of this analysis indicates that the fields are indeed comparable for our GRPLmax thresholds (Fig. A3). If the GRPLmax thresholds are set to lower values (e.g., GRPLmax $\geq 5 \mathrm{~kg} \mathrm{~m}^{-2}$ ), the GRPLmax fields do often lack a corresponding surface pattern in the graupel/hail mixing ratio, which is why we did not include this lower threshold in our analyses.

As just illustrated, a key advantage of our dynamical downscaling approach is that it allows resimulation of individual days, which are independent of each other in the downscaled simulations (but not in the GCM driver). We can exploit this ability and consider possible sensitivities of our downscaling results to the choice of microphysical parameterization. Specifically, we resimulated the 20 days of GRPLmax $\geq 25 \mathrm{~kg} \mathrm{~m}^{-2}$ using the Morrison scheme (Morrison et al. 2009), which is a double-moment scheme (predicting both mass and 

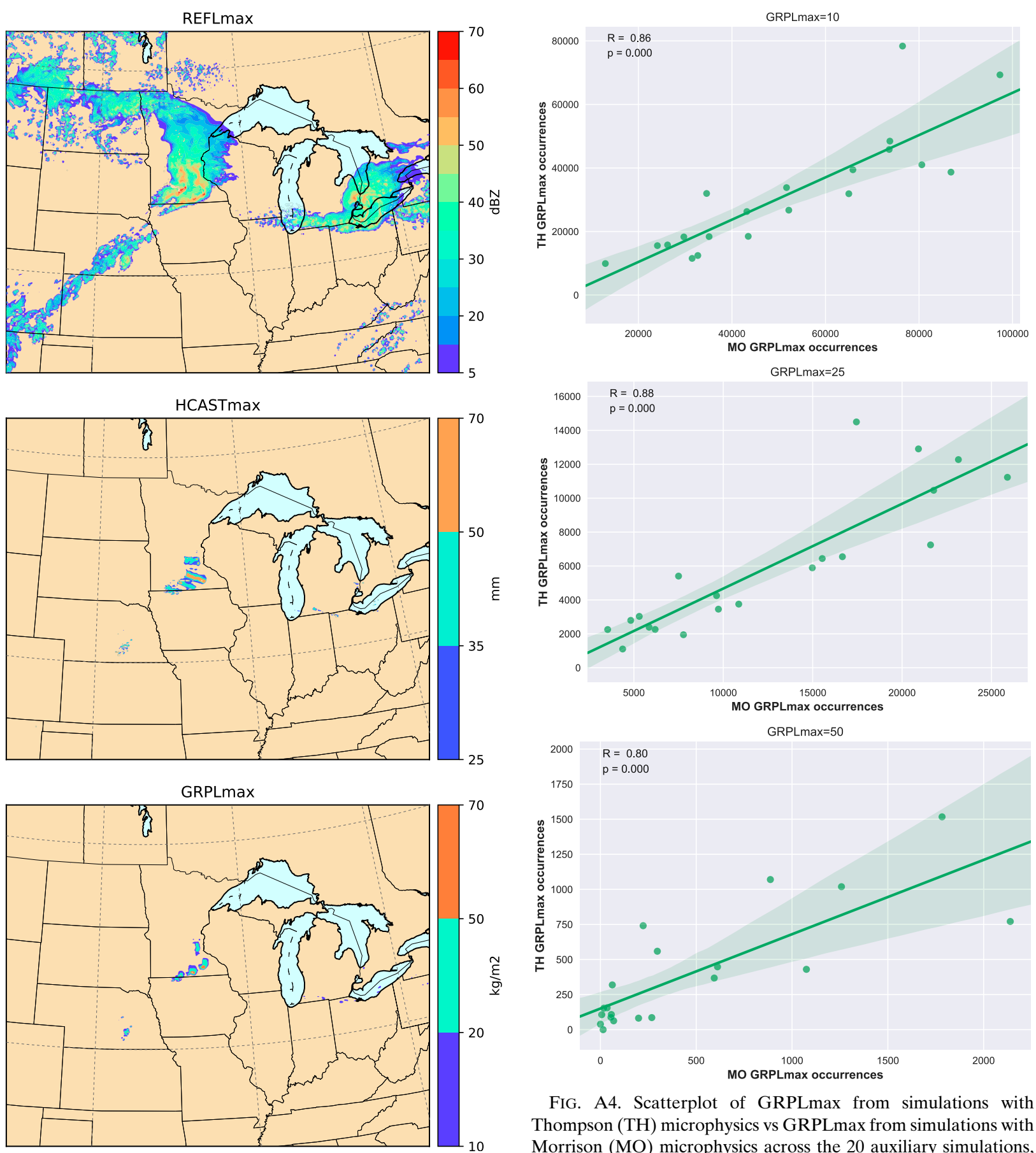

FIG. A4. Scatterplot of GRPLmax from simulations with Thompson (TH) microphysics vs GRPLmax from simulations with Morrison (MO) microphysics across the 20 auxiliary simulations,

FIG. A3. Example comparison between fields of maximum simulated radar reflectivity (REFLmax; dBZ), HCASTmax $(\mathrm{mm})$, and GRPLmax $\left(\mathrm{kg} \mathrm{m}^{-2}\right)$, in a historical event at 2100 UTC 4 Aug 1987.

number of hydrometeors at each grid point) and explicitly predicts a hail mixing ratio. The scatterplots in Fig. A4 reveal statistically significant correlations between GRPLmax occurrences for each of the same three thresholds $\left(10,25\right.$, and $\left.50 \mathrm{~kg} \mathrm{~m}^{-2}\right)$, albeit with increases for 3 GRPLmax thresholds: GRPLmax $\geq 10 \mathrm{~kg} \mathrm{~m}^{-2}$, GRPLmax $\geq$ $25 \mathrm{~kg} \mathrm{~m}^{-2}$, and GRPLmax $\geq 50 \mathrm{~kg} \mathrm{~m}^{-2}$.

in scatter ( $p$ values) for increases in threshold. Similarly, the spatial analyses of the GRPLmax occurrences show favorable agreement across the two microphysical schemes (Fig. A5), thus providing further confidence that the downscaling results are not unique to the use of the Thompson scheme. 

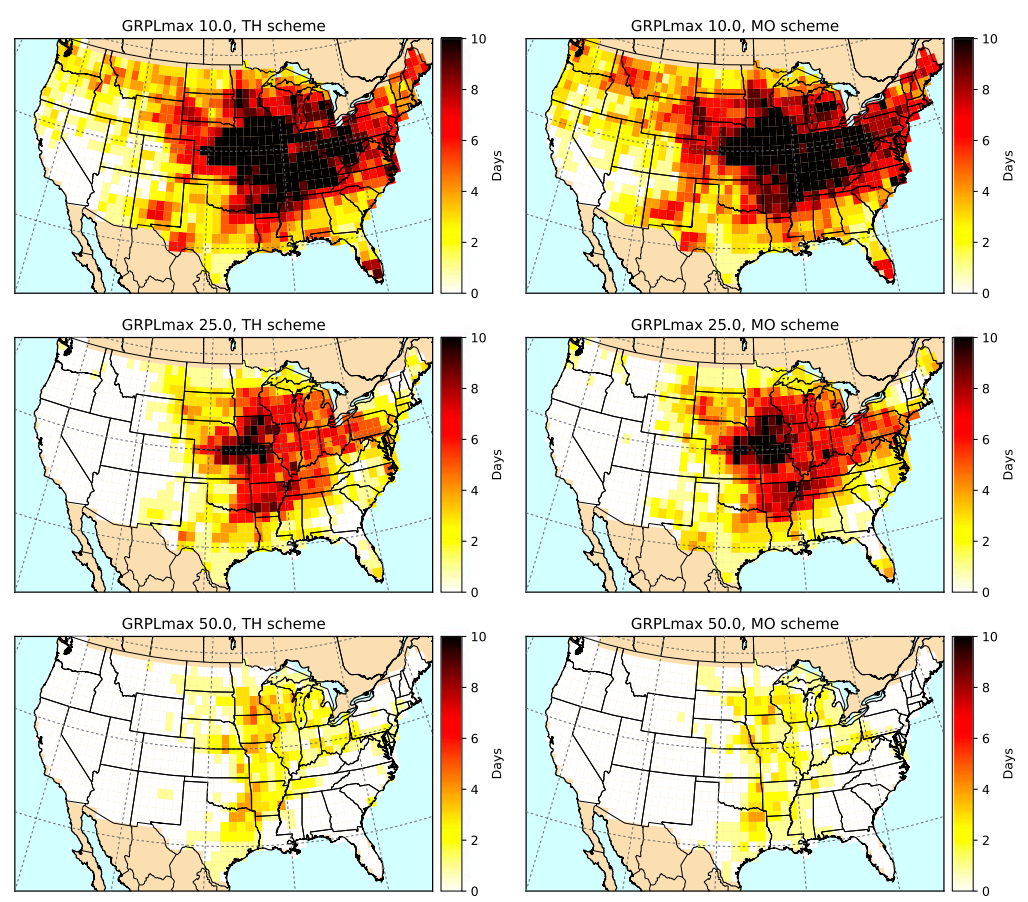

FIG. A5. As in Fig. A2, but for GRPLmax occurrences for each threshold, from simulations with Thompson ( $\mathrm{TH}$ ) microphysics and simulations with Morrison (MO) microphysics.

\section{REFERENCES}

Adams-Selin, R. D., and C. L. Ziegler, 2016: Forecasting hail using a one-dimensional hail growth model within WRF. Mon. Wea. Rev., 144, 4919-4939, https://doi.org/10.1175/MWR-D-16-0027.1.

— A. J. Clark, C. J. Melick, S. R. Dembek, I. L. Jirak, and C. L. Ziegler, 2019: Evolution of WRF-HAILCAST during the 2014-16 NOAA/Hazardous Weather Testbed Spring Forecasting Experiments. Wea. Forecasting, 34, 61-79, https:// doi.org/10.1175/WAF-D-18-0024.1.

Allen, J. T., 2018: Climate change and severe thunderstorms. Oxford Research Encyclopedias: Climate Science, accessed 1 March 2019, https://doi.org/10.1093/acrefore/9780190228620.013.62. , and M. K. Tippett, 2015: The characteristics of United States hail reports: 1955-2014. Electron. J. Severe Storms Meteor., 10 (3), http://www.ejssm.org/ojs/index.php/ejssm/article/view/149.

,-- , and A. H. Sobel, 2015: An empirical model relating U.S. monthly hail occurrence to large-scale meteorological environment. J. Adv. Model. Earth Syst., 7, 226-243, https:// doi.org/10.1002/2014MS000397.

Blair, S. F., and Coauthors, 2017: High-resolution hail observations: Implications for NWS warning operations. Wea. Forecasting, 32, 1101-1119, https://doi.org/10.1175/WAF-D16-0203.1.

Bradley, R. S., F. T. Keimig, H. F. Diaz, and D. R. Hardy, 2009: Recent changes in freezing level heights in the tropics with implications for the deglacierization of high mountain regions. Geophys. Res. Lett., 36, L17701, https://doi.org/10.1029/ 2009GL037712.

Brimelow, J. C., G. W. Reuter, and E. R. Poolman, 2002: Modeling maximum hail size in Alberta thunderstorms. Wea. Forecasting, 17, 1048-1062, https://doi.org/10.1175/15200434(2002)017<1048:MMHSIA > 2.0.CO;2.
— W. R. Burrows, and J. M. Hanesiak, 2017: The changing hail threat over North America in response to anthropogenic climate change. Nat. Climate Change, 7, 516-522, https:// doi.org/10.1038/nclimate3321.

Brooks, H. E., J. W. Lee, and J. P. Craven, 2003: The spatial distribution of severe thunderstorm and tornado environments from global reanalysis data. Atmos. Res., 67-68, 73-94, https:// doi.org/10.1016/S0169-8095(03)00045-0.

, G. W. Carbin, and P. T. Marsh, 2014: Increased variability of tornado occurrence in the United States. Science, 346, 349352, https://doi.org/10.1126/science.1257460.

Del Genio, A. D., M.-S. Yao, and J. Jonas, 2007: Will moist convection be stronger in a warmer climate? Geophys. Res. Lett., 34, L16703, https://doi.org/10.1029/2007GL030525.

Dennis, E. J., and M. R. Kumjian, 2017: The impact of vertical wind shear on hail growth in simulated supercells. J. Atmos. Sci., 74, 641-663, https://doi.org/10.1175/JAS-D-16-0066.1.

Dessens, J., C. Berthet, and J. L. Sanchez, 2015: Change in hailstone size distributions with an increase in the melting level height. Atmos. Res., 158-159, 245-253, https://doi.org/10.1016/ j.atmosres.2014.07.004.

Diffenbaugh, N. S., M. Scherer, and R. J. Trapp, 2013: Robust increases in severe thunderstorm environments in response to greenhouse forcing. Proc. Natl. Acad. Sci. USA, 110, 1636116366, https://doi.org/10.1073/pnas.1307758110.

Doswell, C. A., H. E. Brooks, and M. P. Kay, 2005: Climatological estimates of daily local nontornadic severe thunderstorm probability for the United States. Wea. Forecasting, 20, 577595, https://doi.org/10.1175/WAF866.1.

Gensini, V. A., and T. L. Mote, 2014: Estimations of hazardous convective weather in the United States using dynamical downscaling. J. Climate, 27, 6581-6589, https://doi.org/ 10.1175/JCLI-D-13-00777.1. 
- and T. Mote, 2015: Downscaled estimates of late 21st century severe weather from CCSM3. Climatic Change, 129, 307-321, https://doi.org/10.1007/s10584-014-1320-z.

— C. Ramseyer, and T. L. Mote, 2014: Future convective environments using NARCCAP. Int. J. Climatol., 34, 1699-1705, https://doi.org/10.1002/joc.3769.

Hoogewind, K. A., M. E. Baldwin, and R. J. Trapp, 2017: The impact of climate change on hazardous convective weather in the United States: Insight from high-resolution dynamical downscaling. J. Climate, 30, 10 081-10100, https://doi.org/ 10.1175/JCLI-D-16-0885.1.

Houze, R. A., D. C. Wilton, and B. F. Smull, 2007: Monsoon convection in the Himalayan region as seen by the TRMM Precipitation Radar. Quart. J. Roy. Meteor. Soc., 133, 13891411, https://doi.org/10.1002/qj.106.

Kain, J. S., and Coauthors, 2008: Some practical considerations regarding horizontal resolution in the first generation of operational convection-allowing NWP. Wea. Forecasting, 23, 931-952, https://doi.org/10.1175/WAF2007106.1.

Knight, C. A., and N. C. Knight, 2001: Hailstorms. Severe Convective Storms, Meteor. Monogr., Vol. 50, Amer. Meteor. Soc., 223-248, https://doi.org/10.1175/0065-940128.50.223.

Kumjian, M. R., Z. J. Lebo, and A. M. Ward, 2019: Storms producing large accumulations of small hail. J. Appl. Meteor. Climatol., 58, 341-364, https://doi.org/10.1175/JAMC-D-18-0073.1.

Leslie, L. M., M. Leplastrier, and B. W. Buckley, 2008: Estimating future trends in severe hailstorms over the Sydney Basin: A climate modelling study. Atmos. Res., 87, 37-51, https:// doi.org/10.1016/j.atmosres.2007.06.006.

Mahoney, K., M. A. Alexander, G. Thompson, J. J. Barsugli, and J. D. Scott, 2012: Changes in hail and flood risk in high-resolution simulations over Colorado's mountains. Nat. Climate Change, 2, 125-131, https://doi.org/10.1038/nclimate1344.

Marion, G. R., and R. Trapp, 2019: The dynamical coupling of convective updrafts, downdrafts, and cold pools in simulated supercell thunderstorms. J. Geophys. Res. Atmos., 124, 664683, https://doi.org/10.1029/2018JD029055.

Morrison, H., G. Thompson, and V. Tatarskii, 2009: Impact of cloud microphysics on the development of trailing stratiform precipitation in a simulated squall line: Comparison of oneand two-moment schemes. Mon. Wea. Rev., 137, 991-1007, https://doi.org/10.1175/2008MWR2556.1.

Nelson, S. P., 1983: The influence of storm flow structure on hail growth. J. Atmos. Sci., 40, 1965-1983, https://doi.org/10.1175/ 1520-0469(1983)040<1965:TIOSFS $>2.0$.CO;2.

—, 1987: The hybrid multicellular-supercellular storm-An efficient hail producer. Part II. General characteristics and implications for hail growth. J. Atmos. Sci., 44, 2060-2073, https:// doi.org/10.1175/1520-0469(1987)044<2060:THMSEH>2.0.CO;2.

Nisi, L., O. Martius, A. Hering, M. Kunz, and U. Germann, 2016: Spatial and temporal distribution of hailstorms in the Alpine region: A long-term, high resolution, radar-based analysis. Quart. J. Roy. Meteor. Soc., 142, 1590-1604, https://doi.org/10.1002/qj.2771.

Pendergrass, A. G., R. Knutti, F. Lehner, C. Deser, and B. M. Sanderson, 2017: Precipitation variability increases in a warmer climate. Sci. Rep., 7, 17966, https://doi.org/10.1038/s41598-017-17966-y.

Prein, A. F., C. Liu, K. Ikeda, S. B. Trier, R. M. Rasmussen, G. J. Holland, and M. P. Clark, 2017: Increased rainfall volume from future convective storms in the US. Nat. Climate Change, 7, 880-884, https://doi.org/10.1038/s41558-017-0007-7.

Rasmussen, R., and H. R. Pruppacher, 1982: A wind tunnel and theoretical study of the melting behavior of atmospheric ice particles. I: A wind tunnel study of frozen drops of radius $<500 \mu \mathrm{m}$. J. Atmos. Sci., 39, 152-158, https://doi.org/10.1175/ 1520-0469(1982)039<0152:AWTATS > 2.0.CO;2.

Schauwecker, S., and Coauthors, 2017: The freezing level in the tropical Andes, Peru: An indicator for present and future glacier extents. J. Geophys. Res., 122, 5172-5189, https:// doi.org/10.1002/2016JD025943.

Seeley, J. T., and D. M. Romps, 2015: The effect of global warming on severe thunderstorms in the United States. J. Climate, 28, 2443-2458, https://doi.org/10.1175/JCLI-D-14-00382.1.

Skamarock, W. C., J. B. Klemp, J. Dudhia, D. O. Gill, D. M. Barker, X.-Y. Huang, W. Wang, and J. G. Powers, 2008: A description of the Advanced Research WRF version 3. NCAR Tech. Note NCAR/TN-475+STR, 113 pp., doi:10.5065/D68S4MVH.

Smith, B. T., R. L. Thompson, J. S. Grams, C. Broyles, and H. E. Brooks, 2012: Convective modes for significant severe thunderstorms in the contiguous United States. Part I: Storm classification and climatology. Wea. Forecasting, 27, 11141135, https://doi.org/10.1175/WAF-D-11-00115.1.

Thompson, G., P. R. Field, R. M. Rasmussen, and W. D. Hall, 2008: Explicit forecasts of winter precipitation using an improved bulk microphysics scheme. Part II: Implementation of a new snow parameterization. Mon. Wea. Rev., 136, 5095-5115, https://doi.org/10.1175/2008MWR2387.1.

Tippett, M. K., 2014: Changing volatility of U.S. annual tornado reports. Geophys. Res. Lett., 41, 6956-6961, https://doi.org/ 10.1002/2014GL061347.

Trapp, R. J., and K. A. Hoogewind, 2016: The realization of extreme tornadic storm events under future anthropogenic climate change. J. Climate, 29, 5251-5265, https://doi.org/ 10.1175/JCLI-D-15-0623.1.

, and - 2018: Exploring a possible connection between U.S. tornado activity and Arctic sea ice. npj Climate Atmos. Sci., 1, 14, https://doi.org/10.1038/s41612-018-0025-9.

, N. S. Diffenbaugh, H. E. Brooks, M. E. Baldwin, E. D. Robinson, and J. S. Pal, 2007: Changes in severe thunderstorm environment frequency during the 21 st century caused by anthropogenically enhanced global radiative forcing. Proc. Natl. Acad. Sci. USA, 104, 19719-19723, https://doi.org/ 10.1073/pnas.0705494104.

_ , _ - and A. Gluhovsky, 2009: Transient response of severe thunderstorm forcing to elevated greenhouse gas concentrations. Geophys. Res. Lett., 36, L01703, https://doi.org/10.1029/2008GL036203.

_ E. Robinson, M. Baldwin, N. Diffenbaugh, and B. J. Schwedler, 2011: Regional climate of hazardous convective weather through high-resolution dynamical downscaling. Climate Dyn., 37, 677688, https://doi.org/10.1007/s00382-010-0826-y.

Wang, S., M. Zhang, N. C. Pepin, Z. Li, M. Sun, X. Huang, and Q. Wang, 2014: Recent changes in freezing level heights in High Asia and their impact on glacier changes. J. Geophys. Res., 119, 1753-1765, https://doi.org/10.1002/2013JD020490.

Wilks, D. S., 2016: "The stippling shows statistically significant grid points": How research results are routinely overstated and overinterpreted, and what to do about it. Bull. Amer. Meteor. Soc., 97, 2263-2273, https://doi.org/10.1175/BAMS-D-1500267.1.

Ziegler, C. L., P. S. Ray, and N. C. Knight, 1983: Hail growth in an Oklahoma multicell storm. J. Atmos. Sci., 40, 1768-1791, https:// doi.org/10.1175/1520-0469(1983)040<1768:HGIAOM>2.0.CO;2.

Zou, T., Q. Zhang, W. Li, and J. Li, 2018: Responses of hail and storm days to climate change in the Tibetan Plateau. Geophys. Res. Lett., 45, 4485-4493, https://doi.org/10.1029/ 2018GL077069. 